\title{
Original
} Article

\section{A Clinicopathological Study of Resected Small-Sized Squamous Cell Carcinomas of the Peripheral Lung: Prognostic Significance of Serum Carcinoembryonic Antigen Levels}

\author{
Takuya Nagashima, MD, ${ }^{1}$ Yukinori Sakao, MD, PhD, ${ }^{1}$ Mingyon Mun, MD, PhD,${ }^{1}$ \\ Yuichi Ishikawa, MD, PhD, ${ }^{2}$ Ken Nakagawa, MD, ${ }^{1}$ Munetaka Masuda, MD, PhD ${ }^{3}$ \\ and Sakae Okumura, $\mathrm{MD}^{1}$
}

\begin{abstract}
Purpose: The purpose of this retrospective study was to evaluate common clinicopathological factors and clarify the prognostic factors of small-sized peripheral-lung squamous cell carcinomas.

Methods: We retrospectively reviewed 71 patients with peripheral squamous cell carcinoma $\leq 3 \mathrm{~cm}$ in diameter, who were surgically treated between January 1989 and December 2010. Patients undergoing partial lung resection without lymph node dissection were excluded. The median follow-up for living patients was 63 months.

Results: The overall 3- and 5-year survival rates were $83.9 \%$ and $74.7 \%$, respectively. Although the ROC curve of serum carcinoembryonic antigen (CEA) levels showed marginally significance $(P=0.050)$, multivariate analyses revealed that age $(P=0.043)$, lymph node metastasis $(P=0.004)$, and preoperative serum carcinoembryonic antigen $(\mathrm{CEA})$ level $(P=0.037)$ were independent prognostic factors. For pathologic N0 patients, there was a significant difference for recurrence-free survival based on CEA levels: patients with normal CEA levels $(n=40)$, 5-year-recurrence-free rate $=93.5 \%$; elevated CEA $(n=14)$, 5-year-recurrence-free rate $=72.7 \%(P=0.0160)$. The distribution of tumor cells immunoreactive for CEA was significantly associated with serum CEA levels $(P=0.033)$.

Conclusion: Age, lymph node metastasis, and serum CEA level are independent prognostic factors for small-sized peripheral-lung squamous cell carcinoma.
\end{abstract}

Keywords: squamous cell cancer, lung cancer, carcinoembryonic antigen

${ }^{1}$ Department of Thoracic Surgical Oncology, Japanese Foundation for Cancer Research, Cancer Institute Hospital, Tokyo, Japan

${ }^{2}$ Department of Pathology, Japanese Foundation for Cancer Research, Cancer Institute Hospital, Tokyo, Japan

${ }^{3}$ Department of Surgery, Yokohama City University School of Medicine, Yokohama, Japan

Received: November 11, 2011; Accepted: May 23, 2012 Corresponding author: Yukinori Sakao, MD, PhD. Department of Thoracic Surgical Oncology, Japanese Foundation for Cancer Research, Cancer Institute Hospital, 3-10-6, Ariake, Koto-ku, Tokyo 135-8550, Japan

Email: ysakao@aichi-cc.jp

C2012 The Editorial Committee of Annals of Thoracic and Cardiovascular Surgery. All rights reserved.

\section{Introduction}

Among small-sized peripheral-lung carcinomas, adenocarcinoma is the most common histological type. The incidence of squamous cell carcinomas arising from peripheral lung has been increasing, although in the past, most squamous cell lung carcinomas were reported to develop in the central region of the lung. ${ }^{1-3)}$ While the characteristics of small-sized peripheral adenocarcinomas have been thoroughly investigated, there have only been a few reports published on the prognostic factors of smallsized peripheral-lung squamous cell carcinomas. ${ }^{3-6)}$

In a 2006 study of patients with small $(\leq 30 \mathrm{~mm}$ in diameter) peripheral squamous cell tumors, 
Maeshima et al. proposed that the size of the minimal tumor nest (defined as the smallest group of tumor cells observed in the primary tumor), a background of typical interstitial pneumonia, and lymph node metastasis were significant clinicopathological prognostic factors. ${ }^{5)}$ In 2003, Funai et al. proposed a classification of 3 subgroups, which was based on histological growth patterns and the conditions of the elastic framework of the alveolar septa; these investigators found that alveolar space-filling tumors were noninvasive cancers, irrespective of tumor size. ${ }^{3)}$

Although the factors described in these studies may be useful prognostic factors for small-sized peripherallung squamous cell carcinoma, this has not yet been confirmed. In this retrospective study, we evaluated common clinicopathological variables of patients with small-sized peripheral-lung squamous cell tumors in an attempt to identify prognostic factors.

\section{Materials and Methods}

\section{Patients}

During a 20-year period from January 1989 through December 2010, 2681 patients underwent surgical resection for primary lung carcinoma at the Cancer Institute Hospital of the Japanese Foundation for Cancer Research in Tokyo. Patients with synchronous double cancers and patients who underwent partial lung resection without lymph node dissection because of conditions such as cardiac or pulmonary disorders were excluded. A total of 71 patients with peripheral squamous cell carcinoma $\leq 3 \mathrm{~cm}$ in diameter were included in this analysis. None of these patients had received preoperative treatments. All surgical specimens were pathologically demonstrated to be free of tumor cells at the surgical margins.

Peripheral-lung squamous cell carcinoma was defined as a tumor located in or more peripheral to the fourth branching bronchus. Tumor histology was determined using the World Health Organization classification. Pathological stage was determined according to the seventh edition of the TNM classification for lung cancer.

A total of 64 patients underwent lobectomy (one or more lobes) with lymph node dissection, and 7 patients underwent segmentectomy with lymph node sampling. The outcomes for all 71 patients were determined over a median follow-up time for surviving patients of 63 months (range: 0 to 186 months).
The following data were extracted and analyzed from patient files: age, sex, smoking index $(<1000$ vs. $\geq 1000$ ), pathologic stage (IA vs. IB-IIIB), tumor size (10-20 mm vs. 21-30 mm), nodal status, vessel invasion, pleural invasion, differentiation (well- or moderately-differentiated vs. poorly-differentiated), preoperative serum carcinoembryonic antigen (CEA) levels, and preoperative serum squamous cell carcinoma antigen (SCC) levels.

\section{Serum CEA levels and CEA immunostaining}

Serum CEA levels were determined as part of the routine preoperative evaluation using a microparticle enzyme immunoassay (MEIA) and Abbot AxSYM instrumentation. To elucidate why serum CEA levels were elevated in patients with small-sized peripherallung squamous cell carcinoma, tumor specimens were immunostained for CEA expression. After pathologic assessment of hematoxylin-and-eosin stained slides of sections of surgical specimens, slides with the largest tumor diameters were selected for CEA immunostaining. Staining of slides from all 65 patients was carried out using EnVision+ kits (Dako, Glostrup, Demark) and an anti-CEA mouse monoclonal antibody (Code 422771; Nichirei, Tokyo, Japan). The percentage of CEA-immunoreactive tumor cells was assessed by a pathologist (Y.I) who was blinded to clinical information. Cases that were examined were classified into 4 groups for analysis, according to percentage of CEApositive cells $(0 \%, 1-5 \%, 6-50 \%,>50 \%)$.

\section{Statistical analysis}

Receiver operating characteristic (ROC) curve analysis was performed to assess the sensitivity and specificity of preoperative serum CEA levels for tumor recurrence. The Youden index was used to identify the serum CEA level cut-off value. The duration of recurrence-free survival was determined from the date of surgery to the date of follow-up or recurrence. Five-year recurrence-free survival was determined using the Kaplan-Meier method. Univariate analyses were performed using the log-rank test, and the Cox proportional hazards model was used for multivariate analysis. Variables from univariate analysis with a significance level $\leq 0.10$ were entered into the multivariate model, and backward elimination was used to select variables for the final model, which included variables with a significance value of $\leq 0.05$. The chi-square test was used for comparison of proportions. All analyses were 
Table 1 Clinical characteristics of 71 patients with resected squamous cell carcinoma $(\leq \mathbf{3} \mathrm{cm}$ in diameter)

\begin{tabular}{lc}
\hline Characteristics & Values \\
\hline Age (years) & $47-85$, median 69 \\
Gender & $62 / 9$ \\
Male/Female & \\
Pathological stage & $44 / 6$ \\
IA/IB & $8 / 4$ \\
IIA/IIB & $7 / 2$ \\
IIIA/IIIB & \\
pN factor & $54 / 8 / 8 / 1$ \\
N0/N1/N2/N3 & \\
Tumor size (mm) & $10-30$, median 23 \\
Range & \\
Type of surgery & $2 / 3 / 59 / 7$ \\
Pneumonectomy/Bilobectomy/ \\
$\quad$ Lobectomy/Segmentectomy
\end{tabular}

performed using SPSS software (SPSS Inc., Release 11.0.1J). Differences were considered significant for $P$-values $<0.05$.

\section{Results}

All patients were smokers. Their clinicopathological characteristics are summarized in Table 1. The overall 3- and 5-year survival rates of the 71 evaluated patients were $83.9 \%$ and $74.7 \%$, respectively. A total of 27 patients died from the following: recurrence $(n=10)$, perioperative acute lung injury $(n=1)$, secondary lung cancer $(n=5)$, other cancers $(n=4)$, pneumonia $(n=4)$, and other diseases $(n=3)$. Because there were more non-disease-specific deaths than diseasespecific deaths, recurrence-free survival rates were used to determine prognostic factors. Recurrence-free 3- and 5-year survival rates were $89.2 \%$ and $81.2 \%$, respectively. Twelve patients developed recurrence (16.9\%), including 6 locoregional and 6 distant recurrences.

The ROC curve of CEA levels had an area under the curve of $0.680(P=0.050$, Fig. 1). The Youden index identified $4.05 \mathrm{ng} / \mathrm{mL}$ as the optimal cut-off CEA value for predicting recurrence. Moreover, to determine the best preoperative serum CEA level cut-off point for the probability of recurrence-free survival, 4 values were evaluated: $3.5,4.0,4.5$, and $5.0 \mathrm{ng} / \mathrm{mL}$, and $4.0 \mathrm{ng} / \mathrm{mL}$ provided the lowest log-rank $P$-value. For evaluation of preoperative serum SCC levels, a cut-off value of $1.5 \mathrm{ng} / \mathrm{mL}$ was used. This value was determined by the serum SCC assay manufacturer, and no other values provided a significant difference in our analysis (data not shown).

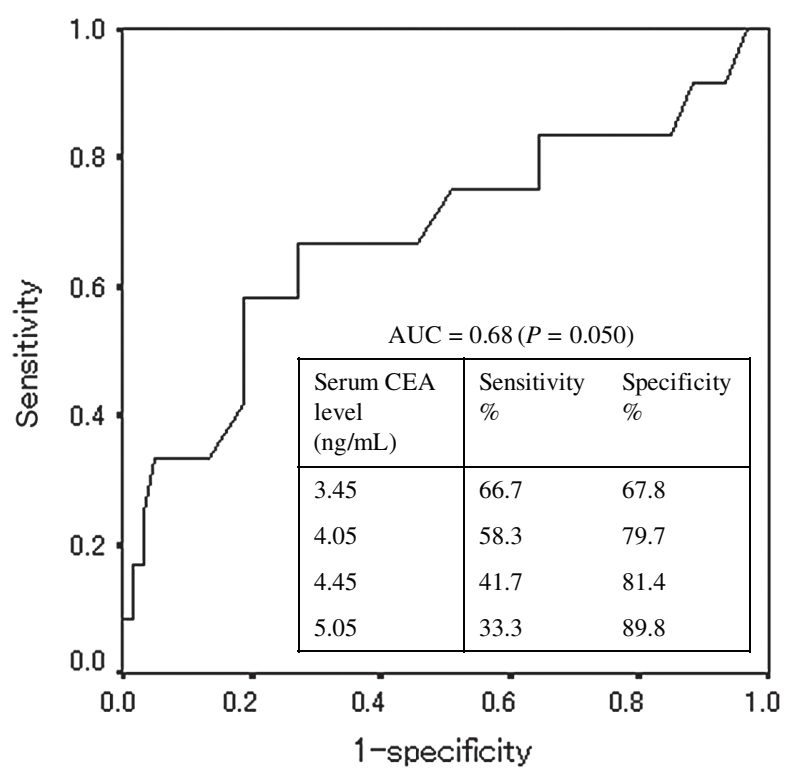

Fig. 1 Receiver operating characteristic (ROC) curve analysis was used to assess the sensitivity and specificity of preoperative serum carcinoembryonic antigen (CEA) levels for tumor recurrence. The Youden index was used to identify the optimal cutoff point of $4.05 \mathrm{ng} / \mathrm{mL}$ for predicting recurrence.

Univariate analyses of the clinicopathological factors listed in Table 2 showed that pathologic stage, presence of lymph node metastasis, vessel invasion, and serum CEA level ( $\leq 4.0$ vs. $>4.0 \mathrm{ng} / \mathrm{mL}$ ) were significant prognostic factors, while age was a marginally significant prognostic factor. In contrast, sex, smoking index, tumor size ( $\leq 20$ vs. $>20 \mathrm{~mm}$ ), lymphatic invasion, pleural invasion, differentiation, and serum SCC level ( $\leq 1.5$ vs. $>1.5 \mathrm{ng} / \mathrm{mL}$ ) were not significant prognostic factors.

Multivariate analysis showed that age $(P=0.043)$, lymph node metastasis $(P=0.004)$, and serum CEA level $(P=0.037)$ were independent prognostic factors; pathologic stage and vessel invasion were eliminated from the final model (Table 3).

Figure 2 shows the overall survival curves and recurrence-free survival curves grouped by CEA concentrations. There was a significant difference for recurrence-free survival $(P=0.0097)$, but not for overall survival $(P=0.30)$.

Figure 3 shows the recurrence-free survival curves for pathologic N0 patients with small-sized peripheral squamous cell lung carcinoma grouped by CEA concentrations. There was a significant difference for recurrence-free survival based on CEA levels: patients 
Table 2 Clinico-pathological variables as possible prognostic factors (univariate analysis)

\begin{tabular}{|c|c|c|c|}
\hline $\begin{array}{l}\text { Clinico-pathological } \\
\text { variables }\end{array}$ & Number & $\begin{array}{c}\text { 5-year } \\
\text { disease-free } \\
\text { survival }\end{array}$ & $\begin{array}{c}\text { Univariate } \\
\text { analysis } \\
\text { ( } p \text {-value) }\end{array}$ \\
\hline Age & 71 & & 0.0540 \\
\hline \multicolumn{4}{|l|}{ Sex } \\
\hline Male & 62 & $80.7 \%$ & \multirow[t]{2}{*}{0.8208} \\
\hline Female & 9 & $88.9 \%$ & \\
\hline \multicolumn{4}{|l|}{ Smoking index } \\
\hline $100-1000$ & 31 & $84.9 \%$ & \multirow[t]{2}{*}{0.6306} \\
\hline $1000<$ & 40 & $79.1 \%$ & \\
\hline \multicolumn{4}{|l|}{ Pathologic stage } \\
\hline IA & 44 & $91.0 \%$ & \multirow[t]{2}{*}{0.0213} \\
\hline IB-IIIB & 27 & $65.9 \%$ & \\
\hline \multicolumn{4}{|l|}{ Tumor size (mm) } \\
\hline $10-20$ & 24 & $90.3 \%$ & \multirow[t]{2}{*}{0.4232} \\
\hline $21-30$ & 47 & $76.4 \%$ & \\
\hline \multicolumn{4}{|l|}{$\begin{array}{l}\text { Lymph node } \\
\text { metastasis }\end{array}$} \\
\hline Negative & 54 & $88.0 \%$ & \multirow[t]{2}{*}{0.0075} \\
\hline Positive & 17 & $57.5 \%$ & \\
\hline \multicolumn{4}{|l|}{ Lymphatic invasion } \\
\hline Negative & 58 & $85.6 \%$ & \multirow[t]{2}{*}{0.1109} \\
\hline Positive & 13 & $62.5 \%$ & \\
\hline \multicolumn{4}{|l|}{ Vessel invasion } \\
\hline Negative & 27 & $95.8 \%$ & \multirow[t]{2}{*}{0.0445} \\
\hline Positive & 44 & $71.1 \%$ & \\
\hline \multicolumn{4}{|l|}{ Pleural invasion } \\
\hline Negative & 62 & $84.3 \%$ & \multirow[t]{2}{*}{0.2523} \\
\hline Positive & 9 & $64.8 \%$ & \\
\hline \multicolumn{4}{|l|}{ Differentiation } \\
\hline Well or moderate & 40 & $82.3 \%$ & \multirow[t]{2}{*}{0.3188} \\
\hline Poor & 31 & $79.6 \%$ & \\
\hline \multicolumn{4}{|l|}{ Serum CEA (ng/ml) } \\
\hline$\leqq 4.0$ & 52 & $88.2 \%$ & \multirow[t]{2}{*}{0.0097} \\
\hline$>4.0$ & 19 & $63.5 \%$ & \\
\hline \multicolumn{4}{|l|}{ Serum SCC (ng/ml) } \\
\hline$\leqq 1.5$ & 40 & $83.9 \%$ & \multirow[t]{4}{*}{0.4267} \\
\hline$>1.5$ & 19 & $71.4 \%$ & \\
\hline Unknown & 12 & & \\
\hline Total & 71 & & \\
\hline
\end{tabular}

CEA: carcinoembryonic antigen; SCC: squamous cell carcinoma antigen

with CEA $\leq 4.0 \mathrm{ng} / \mathrm{mL}(n=40), 5$-year recurrence-free rate $=93.5 \%$; patients with CEA $>4.0 \mathrm{ng} / \mathrm{mL}(n=14)$, 5 year recurrence-free rate $=72.7 \%(P=0.0160)$.

Among pathologic N-positive patients, there was no significant difference for recurrence-free survival based on CEA levels: patients with CEA $\leq 4.0 \mathrm{ng} / \mathrm{mL}$ $(n=12), 5$-year-recurrence-free rate $=66.3 \%$; patients with CEA $>4.0 \mathrm{ng} / \mathrm{mL}(n=5)$; 5-year-recurrence-free rate $=21.9 \%(P=0.3057)$.

Sixty-eight percent of the 65 tumors analyzed were positive for CEA staining. The distribution of tumor
Table 3 Multivariate analysis of clinicopathological variables as prognostic factors of recurrence-free survival

\begin{tabular}{lccc}
\hline Prognostic factors & Hazard ratio & $95 \%$ CI & $P$ \\
\hline Age & 1.118 & $1.015-1.232$ & 0.024 \\
Lymph node metastasis & 5.281 & $1.648-16.922$ & 0.005 \\
Serum CEA & 4.228 & $1.304-13.701$ & 0.016 \\
\hline
\end{tabular}

CI: confidence interval; CEA: preoperative serum carcinoembryonic antigen

cells immunoreactive for CEA was significantly associated with serum CEA levels $(P=0.033$, Table 4).

\section{Discussion}

In this study, multivariate analysis identified age, lymph node metastasis, and preoperative serum CEA concentration as prognostic indicators for small-sized $(\leq 3 \mathrm{~cm})$ squamous cell carcinoma of the peripheral lung. Age and lymph node metastasis had also been previously reported to be prognostic factors for squamous cell carcinoma of the peripheral lung. ${ }^{5)}$

There have been several studies reporting that age was an independent prognostic factor for non-small cell lung cancer. ${ }^{5-9)}$ Some of these studies also showed that age was an independent prognostic factor for pathologic stage I non-small cell lung cancer. ${ }^{7,8)}$ Another study showed that younger patients with non-small cell lung cancer had significantly better recurrence-free survival than older patients. The investigators of that study suggested that the reasons that age was an independent prognostic factor might involve the differences between activated oncogenic pathways and the types of tumor microenvironment in young and old patients. ${ }^{9)}$

Our study found that the serum CEA level was an independent prognostic factor for patients with smallsized peripheral-lung squamous cell carcinoma. Not only is this the first study to evaluate serum CEA levels in patients with peripheral-lung squamous cell carcinoma, it is also the first to show a significant association between CEA levels and prognosis.

Serum CEA levels have been shown to be elevated in patients with squamous cell carcinoma of the esophagus and the uterine cervix. ${ }^{10-12)}$ Moreover, one report showed that serum CEA was associated with clinical stage and distant metastasis in esophageal cancer, ${ }^{11)}$ and another report showed that the pretreatment serum CEA level was a prognostic factor in cancer of the uterine cervix. ${ }^{12)}$ Although no patient in our study had a past 

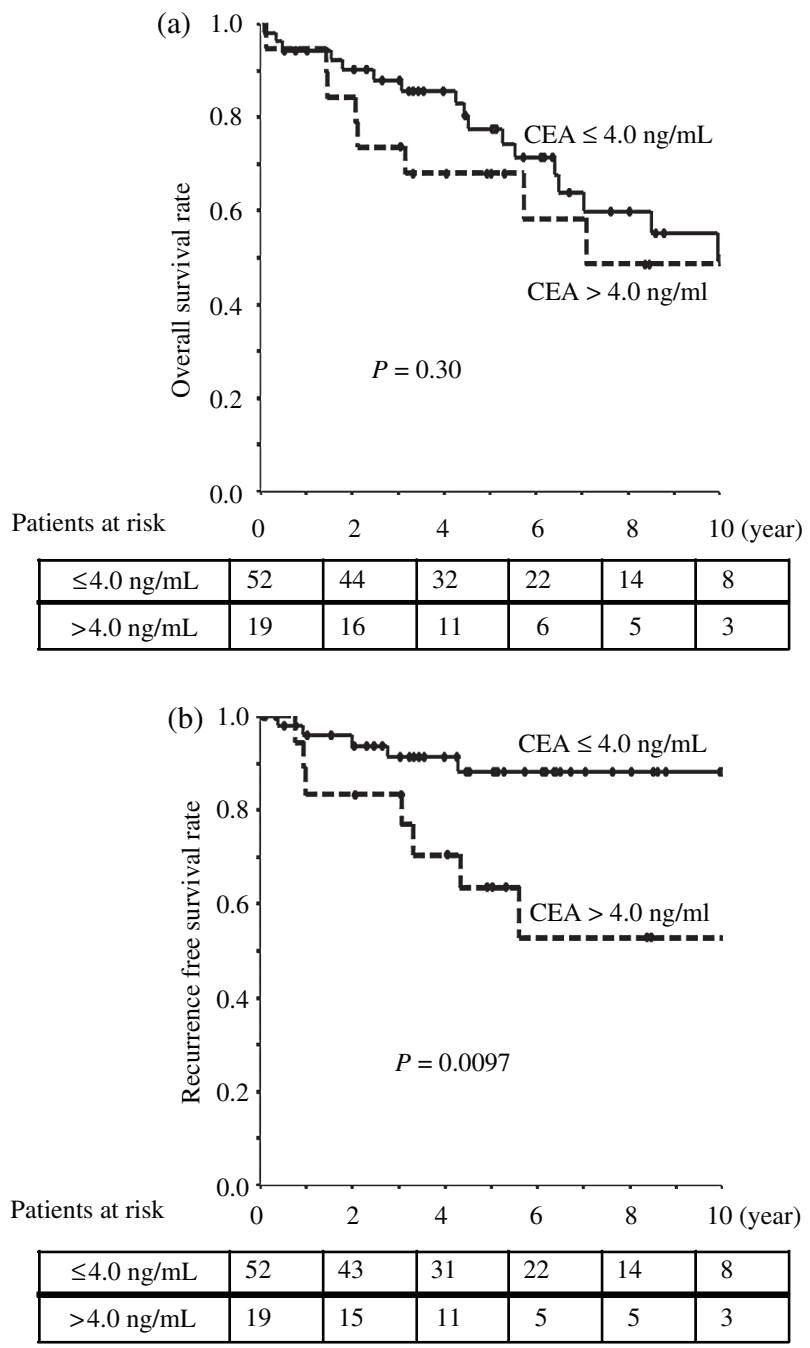

Fig. 2 Overall survival curves (a) and recurrence-free survival curves (b) grouped by carcinoembryonic antigen (CEA) concentrations.

history of other carcinomas, because it is sometimes difficult to differentiate histologically between primary squamous cell carcinoma of the lung and metastatic squamous cell carcinoma from other organs, the possibility of metastatic disease should be considered when diagnosing lung nodules associated with high serum CEA levels.

Most studies of head and neck squamous cell carcinomas have shown that the serum CEA level was not a prognostic factor, ${ }^{13,14)}$ and some reports demonstrated that the CEA level was more reflective of the alcohol consumption and smoking habits of their patients than disease status. ${ }^{15,16)}$ In our study, the serum CEA level was not related to the smoking index.

Elevated serum CEA levels have been observed in some studies of squamous cell lung carcinoma,

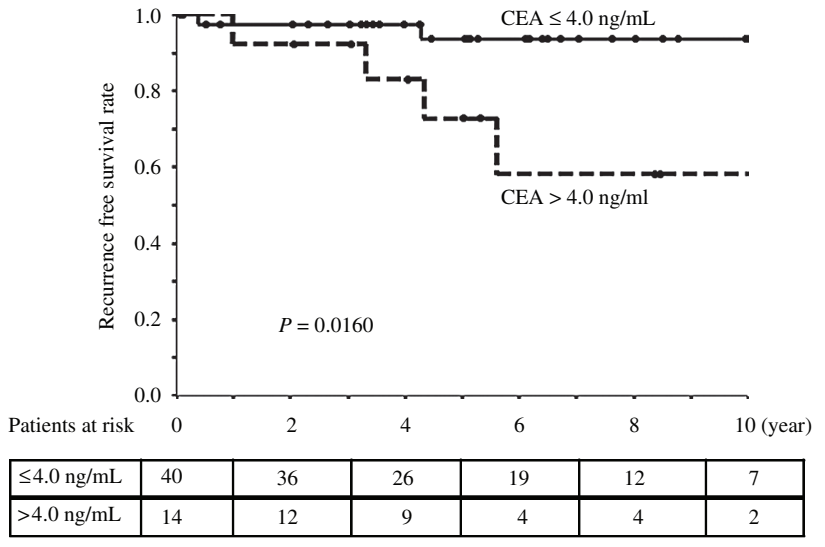

Fig. 3 Recurrence-free survival curves of pathologic N0 patients with small-sized peripheral-lung squamous cell carcinoma based on preoperative serum carcinoembryonic antigen (CEA) levels.

regardless of tumor location. ${ }^{17-20)}$ Whether or not the serum CEA level is a prognostic factor for this tumor type remains controversial, and the preoperative serum CEA level cut-off value for squamous cell carcinoma of the peripheral lung has not been clarified.

In this study, the ROC curve of CEA levels for predicting recurrence showed marginally significance $(P=0.050$, Fig. 1). Although this data did not show CEA levels was an absolutely significant indicator for prediction of recurrence, our results showed a significantly low recurrence-free survival rate for patients whose preoperative CEA concentration was $>4.0 \mathrm{ng} / \mathrm{mL}$. It was suggested that the serum CEA levels was one of the promising predictive factors for tumor recurrence in small peripheral squamous cell carcinomas. On the other hand, there was no significant difference for overall survival based on CEA levels. This may be explained the fact that there were more non-disease-specific deaths than disease-specific deaths.

Tomita et al. concluded that the serum CEA level was not a prognostic factor fo squamous cell carcinoma of the lung. ${ }^{19)}$ In contrast, Tas et al. showed that the serum CEA level was significantly elevated in patients with stage IV squamous cell carcinoma; ${ }^{17)}$ Kulpa et al. showed that serum CEA levels were significantly different between operable and inoperable patients, ${ }^{18)}$ and Body et al. showed that an elevated CEA level was an adverse prognostic factor for squamous cell carcinoma of the lung. ${ }^{20)}$ However, these reports did not separately evaluate central-type versus peripheral-type tumors. In previous reports, the prevalence of peripheraltype lesions among all squamous cell carcinomas of the 
Table 4 Relationship of preoperative serum carcinoembryonic antigen (CEA) levels and tumors with specified percentages of CEA-positive cells

\begin{tabular}{lrrrrr}
\hline & \multicolumn{5}{c}{ Percentage of CEA } \\
& \multicolumn{5}{c}{ immunoreactive tumor cells } \\
\cline { 2 - 6 } & $0 \%$ & $1-5 \%$ & $6-50 \%$ & $>50 \%$ & $P$ \\
\hline $\begin{array}{l}\text { Serum CEA }(\mathrm{ng} / \mathrm{ml}) \\
\leqq 4.0\end{array}$ & 17 & 20 & 9 & 0 & 0.033 \\
$>4.0$ & 4 & 7 & 5 & 3 & \\
\hline
\end{tabular}

CEA: carcinoembryonic antigen

lung was reported to range from $15 \%$ to $30 \%^{3,21)}$; thus, the varied results were likely influenced by the predominance of central-type lesions. Compared with the conflicting data from the reports we have described, our study focused on peripheral-type tumors only and found that an elevated CEA level was a prognostic factor.

Some reports have evaluated serum CEA levels in small-sized non-small cell lung carcinomas. ${ }^{22-24)}$ These studies indicated that the serum CEA level was a good predictor of a poor prognosis; however, the majority of these studies only examined adenocarcinomas. Matsuguma et al. found that the serum CEA level was a useful prognostic factor not only for adenocarcinoma, but also for nonadenocarcinomas, including squamous cell carcinoma and nonsquamous cell carcinoma, in patients with pathologic stage I non-small cell lung cancers. ${ }^{22)}$ These results plus our findings on small-sized peripheral-lung carcinomas that were not only adenocarcinomas but also squamous cell carcinomas, indicate that the serum CEA level may be a useful prognostic factor.

Our study found that a high serum CEA level was an adverse prognostic factor, particularly for pathologic NO patients. Some previous studies reported that the serum CEA level was associated with advanced stages of lung squamous cell carcinoma, ${ }^{17,18)}$ but not with early stages. However, other studies found that the serum CEA level was a prognostic factor for early-stage non-small cell carcinoma or adenocarcinoma. ${ }^{22-24)}$

There have been some studies of small-sized peripheral adenocarcinomas reporting that a high serum CEA level was a risk factor for lymph node metastases. ${ }^{23,25)}$ In our study, the serum CEA level was not associated with lymph node metastases. Furthermore, smoking index, differentiation, vascular invasion, lymphatic invasion, and tumor size were not associated with serum CEA levels.

Because of our findings, we examined tumor specimens for CEA staining. Limited data on CEA expression in lung cancer specimens are available. Some studies demonstrated tumor CEA positivity in a high proportion of squamous cell carcinomas of the lung. ${ }^{26-28)}$ Moreover, one study has reported that peripheral-type tumors more frequently expressed CEA than the central type (but the differences were not significant). ${ }^{28)}$ The results of these studies are similar to our results. In addition, one study found an association between prognosis and the immunostaining pattern of CEA in adenocarcinoma, but we were not able to find any differences in staining patterns in the squamous cell carcinomas of our patients. ${ }^{26)}$

Giulia et al. found that CEA expression was significantly associated with serum CEA levels in patients with non-small cell lung carcinoma, but not in patients with squamous cell carcinoma. ${ }^{26)}$ In our study, however, the distribution of tumor cells immunoreactive for CEA was significantly associated with serum CEA levels $(P=0.033$, Table 4). We think that the different finding in our study may reflect the fact that we only investigated peripheral-type squamous cell carcinomas.

In conclusion, age, lymph node metastasis, and preoperative serum CEA level are independent prognostic factors for small-sized peripheral-lung squamous cell carcinoma.

\section{Disclosure Statement}

The authors have no conflicts of interest.

\section{References}

1) Hammer SP, Petrovichev N, Carvalho L, Brambilla C, Matsuno Y, et al. Squamous cell carcinoma. In: Travis WD, Brambilla E, Muller-Hermelink HK, Harris CC eds.; World Health Organization classification of tumors. Pathology and genetics of tumors of lung, pleura, thymus and heart. Lyon: IARC Press, 2004; pp 26-30.

2) Asamura $H$, Nakayama $H$, Kondo $H$, et al. Lymph node involvement, recurrence, and prognosis in resected small, peripheral, non-small-cell lung carcinomas: are these carcinomas candidates for video-assisted lobectomy? J Thorac Cardiovasc Surg 1996; 111: 1125-34.

3) Funai $K$, Yokose $T$, Ishii $G$, et al. Clinicopathologic characteristics of peripheral squamous cell carcinoma of the lung. Am J Surg Pathol 2003; 27: 978-84.

4) Sakurai $H$, Asamura $H$, Watanabe $S$, et al. Clinicopathologic features of peripheral squamous cell carcinoma of the lung. Ann Thorac Surg 2004; 78: 222-7.

5) Maeshima AM, Maeshima A, Asamura H, et al. Histologic prognostic factors for small-sized squamous cell 
carcinomas of the peripheral lung. Lung Cancer 2006; 52: 53-8.

6) Yousem SA. Peripheral squamous cell carcinoma of lung: patterns of growth with particular focus on airspace filling. Hum Pathol 2009; 40: 861-7.

7) Ou SH, Zell JA, Ziogas A, et al. Prognostic factors for survival of stage I nonsmall cell lung cancer patients: a population-based analysis of 19,702 stage I patients in the California Cancer Registry from 1989 to 2003. Cancer 2007; 110: 1532-41.

8) León-Atance P, Moreno-Mata N, González-Aragoneses $\mathrm{F}$, et al. Multicenter analysis of survival and prognostic factors in pathologic stage I non-small-cell lung cancer according to the new 2009 TNM classification. Arch Bronconeumol 2011; 47: 441-6 (in English, Spanish).

9) Mostertz W, Stevenson M, Acharya C, et al. Age- and sex-specific genomic profiles in non-small cell lung cancer. JAMA 2010; 303: 535-43.

10) Shimada H, Nabeya Y, Okazumi S, et al. Prediction of survival with squamous cell carcinoma antigen in patients with resectable esophageal squamous cell carcinoma. Surgery 2003; 133: 486-94.

11) Kosugi S, Nishimaki T, Kanda $T$, et al. Clinical significance of serum carcinoembryonic antigen, carbohydrate antigen 19-9, and squamous cell carcinoma antigen levels in esophageal cancer patients. World J Surg 2004; 28: 680-5.

12) Chen SW, Liang JA, Hung YC, et al. Clinical implications of elevated pretreatment carcinoembryonic antigen in patients with advanced squamous cell carcinoma of the uterine cervix. Tumour Biol 2008; 29: 255-61.

13) Büntzel J, Hornig A, Glatzel M, et al. Tumor markers and lymphatic metastasis in head and neck cancer patients. Anticancer Res 2005; 25: 1539-42.

14) Kandiloros D, Eleftheriadou A, Chalastras T, et al. Prospective study of a panel of tumor markers as prognostic factors in patients with squamous cell carcinoma of head and neck. Med Oncol 2006; 23: 463-70.

15) Krimmel M, Hoffmann J, Krimmel C, et al. Relevance of SCC-Ag, CEA, CA 19.9 and CA 125 for diagnosis and follow-up in oral cancer. J Craniomaxillofac Surg 1998; 26: 243-8.

16) Costey M, Mora J, León X, et al. CEA and Cyfra 21.1 study pre-treatment in 252 patients with head and neck carcinomas. Acta Otorrinolaringol Esp 2004; 55: 33842. (in Spanish)

17) Tas F, Aydiner A, Topuz E, et al. Utility of the serum tumor markers: CYFRA 21.1, carcinoembryonic antigen (CEA), and squamous cell carcinoma antigen
(SCC) in squamous cell lung cancer. J Exp Clin Cancer Res 2000; 19: 477-81.

18) Kulpa J, Wójcik E, Reinfuss M, et al. Carcinoembryonic antigen, squamous cell carcinoma antigen, CYFRA 21-1, and neuron-specific enolase in squamous cell lung cancer patients. Clin Chem 2002; 48: 1931-7.

19) Tomita M, Matsuzaki Y, Edagawa M, et al. Prognostic significance of preoperative serum carcinoembryonic antigen level in lung adenocarcinoma but not squamous cell carcinoma. Ann Thorac Cardiovasc Surg 2004; 10: 76-80.

20) Body JJ, Sculier JP, Raymakers N, et al. Evaluation of squamous cell carcinoma antigen as a new marker for lung cancer. Cancer 1990; 65: 1552-6.

21) Huhti E, Saloheimo M, Sutinen S, et al. Does the location of lung cancer affect its prognosis? Eur J Respir Dis 1983; 64: 460-5.

22) Matsuguma H, Nakahara R, Igarashi S, et al. Pathologic stage I non-small cell lung cancer with high levels of preoperative serum carcinoembryonic antigen: clinicopathologic characteristics and prognosis. J Thorac Cardiovasc Surg 2008; 135: 44-9.

23) Inoue $M$, Minami $M$, Shiono $H$, et al. Clinicopathologic study of resected, peripheral, small-sized, nonsmall cell lung cancer tumors of $2 \mathrm{~cm}$ or less in diameter: pleural invasion and increase of serum carcinoembryonic antigen level as predictors of nodal involvement. J Thorac Cardiovasc Surg 2006; 131: 988-93.

24) Okada M, Nishio W, Sakamoto T, et al. Prognostic significance of perioperative serum carcinoembryonic antigen in non-small cell lung cancer: analysis of 1,000 consecutive resections for clinical stage I disease. Ann Thorac Surg 2004; 78: 216-21.

25) Sakao Y, Sakuragi T, Natsuaki M, et al. Clinicopathological analysis of prognostic factors in clinical IA peripheral adenocarcinoma of the lung. Ann Thorac Surg 2003; 75: 1113-7.

26) Veronesi G, Pelosi G, Sonzogni A, et al. Tumour CEA as predictor of better outcome in squamous cell carcinoma of the lung. Lung Cancer 2005; 48: 233-40.

27) Okamura A, Ohkawa J, Fujisawa H, et al. Clinicopathological study on the relationship between serumCEA and tissue-CEA of resected lung cancer cases. Acta Pathol Jpn 1984; 34: 1209-19.

28) Saijo T, Ishii G, Nagai K, et al. Differences in clinicopathological and biological features between centraltype and peripheral-type squamous cell carcinoma of the lung. Lung Cancer 2006; 52: 37-45. 